\title{
CONSTRUCCIÓN TEATRAL DEL FESTEJO BARROCO: LOS EMPEÑOS DE UNA CASA DE SOR JUANA ${ }^{1}$
}

\author{
Aurelio GONZÁLEZ \\ El Colegio de México
}

$\mathrm{Al}$ estudiar las obras de teatro del Siglo de Oro y en él sus manifestaciones novohispanas, en muchas ocasiones se olvida que se trata, sin importar que sean montajes palaciegos o de corral, de un espectáculo múltiple, que incluye variadas expresiones y géneros y que tiene diversas intenciones.

El teatro, como espectáculo, podía funcionar como un conjunto escénico festivo formado por varias partes literarias casi nunca escritas por el mismo autor por lo que son raros los casos en que nos ha llegado completo el conjunto de textos. Los ejemplos de fiestas teatrales completas y debidas a un solo autor son aún menos frecuentes ${ }^{2}$ por lo que el estudio de aquellas que han llegado hasta nosotros ofrece posibilidades muy interesantes para la mejor comprensión de técnicas y recursos teatrales. Los empeños de una casa, fiesta barroca novohispana, de Sor Juana nos ofrece esta posibilidad. Independientemente de su representación en fechas y lugares concretos o incluso de composición para un mismo momento, lo que importa es que fue publicada como una unidad (Sevilla, 1692; Barcelona, 1693) lo cual nos da a entender que su autora consideraba que llenaba las expectativas del público y reunía los requisitos para poder funcionar efectivamente como una unidad teatral.

Una versión preliminar de este trabajo se presentó en el Congreso Internacional Sor Juana y su mundo celebrado en la Universidad del Claustro de Sor Juana, México, D. F., del 13 al 17 de noviembre de 1995.

2 Entre los poquísimos ejemplos que tenemos de fiestas teatrales completas de un sólo autor se pueden mencionar Fieras afemina amor (1670) de Calderón, y Por su rey y por su dama (1685) de Bances Candamo. No pasan de una docena los textos conocidos de fiestas completas. 
La fecha del montaje, comúnmente aceptada y según lo señaló Salceda (Sor Juana Inés de la Cruz 1957, pp. XVII y ss.) es el 4 de octubre de 1683, día de la entrada del arzobispo Aguiar y Seijas en la ciudad de México, en casa de Fernando Deza, Contador de Tributos. Susana Hernández Araico ha revisado recientemente esta afirmación y adecuadamente señala que en el Diario de Antonio Robles (Robles [1665] 1946, t. I, p. 56), que sirve de fuente básica para esta datación, no se señala ningún festejo en la casa de Deza, aunque sí recuerda que hubo un arco triunfal y un castillo y también la realización de otros festejos palaciegos (Hernández Araico 1996, pp. 111-112).

Hernández Araico, siguiendo un punto nunca rebatido por Salceda y planteado por Francisco Monterde (Monterde 1946, pp. 56 y ss.) propone con buen fundamento que «la obra se montó entre el nacimiento y el primer cumpleaños del primogénito de los virreyes», y va aun más lejos «hasta poco después del primer cumpleaños del primogénito virreinal, hasta mediados de agosto de 1684, después de haber entrado a la ciudad el obispo de Oaxaca, Sariñana [...]». Pues el miércoles 16 de agosto de 1684 el virrey invitó a cenar a los obispos de Michoacán y Oaxaca, Real Audiencia y Tribunales y el festejo bien pudo celebrarse en la casa de algún noble y «habría sido del todo ocasión propicia para halagar en primer lugar a la familia virreinal y como coda, de ninguna manera ofensiva, a Sariñana -de origen social y prestigio político bastante inferior a los anfitriones» (Hernández Araico 1996, p. 121). Independientemente de la fecha de su representación el hecho es que Los empeños de una casa ha llegado a nosotros como un conjunto de textos dramáticos que fácilmente se identifican con una fiesta teatral barroca; la relación entre las distintas partes es evidente y aun explícita como en el subtítulo de la loa: «para la comedia que sigue», sin embargo llama la atención que las crónicas de la época no hayan recogido la noticia de una fiesta de este tipo debida a sor Juana en honor de los virreyes don Tomás Antonio de la Cerda y Enríquez de Rivera, conde de Paredes y marqués de la Laguna de Camero Viejo y de su esposa.

La relación entre las partes de la obra, la comedia y la loa primera, los sainetes y el sarao y los textos líricos, así como las referencias encomiásticas a los virreyes ya ha sido estudiada desde distintos puntos de vista encontrando abundantes nexos que refuerzan la idea de una unidad y el valor de las distintas partes (Pailler 1973, pp. 60-80 y Poot Herrera 1993, pp. 257-267).

Trabajos recientes de Susana Hernández Araico (1997a y 1997b) sobre la estructura y sentido de Los empeños y de Ruano de la Haza sobre el posible espacio escénico (1991) resultan muy iluminadores sobre el concepto teatral de este festejo barroco y de sus valores innovadores.

Podemos decir que el espectáculo teatral barroco es una entidad compleja que se articula con distintos elementos que por su propia naturaleza o especifici- 
dad genérica tienen funciones particulares en la economía dramática de la representación. Esta unidad, vista en su conjunto, nos presenta una diferencia con respecto a lo que sería su núcleo esencial que es la obra o comedia propiamente dicha. Esta diferencia tiene que ver con el dramaturgo (autor), pero también con el director (también «autor»).

No está por demás recordar que así como el escritor concibe su texto, desde su génesis, como un texto teatral, de acuerdo con convenciones genéricas específicas y con los usos escénicos de su tiempo, el director concibe el espectáculo teatral en consonancia con los mismos presupuestos, desde luego esto tiene el margen de la innovación creativa que hace evolucionar las formas literarias y que hace única cada obra.

En este sentido, tanto el dramaturgo como el director están pendientes de la espacialidad que define al hecho teatral, uno en el momento de crear el texto dramático, el otro en el momento de realizar el texto espectacular en un espacio concreto.

Entonces el espectáculo teatral, de corral o cortesano, se va a conformar habitualmente a partir de un núcleo que es la comedia, texto largo, y un conjunto de elementos ancilares, textos más breves. Por lo general estos elementos ancilares, como hemos dicho antes, han sido compuestos por un autor diferente del que ha escrito la comedia y que además puede ser un especialista en ese tipo de textos breves. Podríamos decir que el director es en realidad el verdadero autor del conjunto espectacular en cuanto representación, ya que él selecciona y estructura sus componentes. Por otra parte, la composición del espectáculo es tan efímera como la misma «función» de ahí que conservemos muy pocos ejemplos de la composición de los espectáculos teatrales.

En la creación del «Festejo de Los empeños de una casa» Sor Juana funciona como autor dramático, pero también como «autor» del montaje ya que la obra está llena de relaciones internas con la puesta en escena, guiños culturales y presencia lírica personal de la autora. La estructura del festejo está formada por las siguientes partes: «Loa, que precedió a la comedia que se sigue», «Letra que se cantó por Divina Fénix, permite», «Los empeños de una casa. Comedia famosa. [...] Jornada primera», «Letra por Bellísimo Narciso», «Sainete primero de palacio», «Jornada segunda», «Letra por Tierno, adorado Adonis», «Sainete segundo», «Jornada tercera» y «Sarao de cuatro naciones» (Sor Juana Inés de la Cruz [1692] 1995, pp. $450-532)^{3}$.

En otro lugar he tratado sobre la complejidad y manejo significativo que hace sor Juana del espacio en la comedia Los empeños de una casa (González

Modernizo la ortografía. 
1993, pp. 269-277), ahora trataré del manejo espacial y escénico en las partes menores que componen esta fiesta teatral barroca de Sor Juana.

La loa tiene «funciones explicativas, de predisposición favorable por la alabanza, de presentación y elogio de la compañía, comicidad, etc., enlazando en su evolución con otras piezas liminares del teatro del XVI (introitos, argumentos, premios...) que habían cumplido parecidas funciones, aunque más vinculadas temáticamente a la obra que acompañan» (Díez Borque 1992, pp. 43-44). En la loa de esta obra de sor Juana todos los interlocutores son figuras alegóricas: La Dicha, La Diligencia, El Acaso, La Fortuna, El Mérito y Música ${ }^{4}$. La trama, de acuerdo con la función de la loa, es sencilla y se reduce a la reclamación que hacen los cuatro interlocutores para que se les atribuya la consecución de la dicha, la cual evidentemente será atribuida a los virreyes a quienes va dedicado el festejo. La loa se inicia con la figura de la Música en escena y convocando a los otros interlocutores. La presencia en el escenario de esta figura nos sugiere que debe ser en la parte posterior del tablado pues de lo contrario el desplazamiento a la vista del público, sin razón dramática que lo justifique, debilita el inicio del espectáculo, que por la muy probable ausencia de telón de boca, debía llamar la atención de los asistentes y en este sentido la entrada discreta del actor por el fondo del escenario desde el vestuario (o por el centro para no estorbar las entradas laterales, casi inmediatas, de las figuras convocadas), posiblemente con música estableciendo una relación con la caracterización del personaje de una manera más que icónica, lo que permite captar la atención del público, lo que se reforzará con el texto del pregón que abre la representación el cual explícitamente reclama la atención general:

$\begin{array}{ll}\text { Música } & \text { Para celebrar cuál es } \\ & \text { De las dichas la mayor, } \\ \text { A la ingeniosa palestra } \\ \text { Convoca a todos mi voz. } \\ \text { ¡Venid al pregón! } \\ \text { ¡Atención, silencio, atención, atención! }\end{array}$

(Loa, 1-6, p. 95)

De esta forma el espacio dramático de la loa es el propio espacio escénico y teatral ${ }^{6}$ ya que involucrará en la parte final a los virreyes situados en lugar de

4 Como ha observado acertadamente Dolores Bravo en el estudio que precede su edición de esta comedia «Para lograr un mayor dinamismo escénico, la autora los agrupa por parejas relacionadas en su significado: Fortuna-Acaso y Diligencia-Mérito», Bravo (1992, p. 53).

5 Cito por la edición de Celsa Carmen García Valdés (Sor Juana Inés de la Cruz [1683] 1989). Indico la jornada o título de la pieza breve y el número de versos, así como la página.

6 Entiendo como espacio dramático el de la ficción, como espacio escénico el de la representación: el tablado y estructuras aledañas y como espacio teatral el que incluye tanto el espacio de la representación como en el que está situado el público. En este sentido puede verse Massip (1992, pp. 45-78). 
privilegio entre el público que con su asistencia a la representación convierte una sala o patio de una casa particular en espacio teatral. La entrada directa del Mérito y la Diligencia por un lado y la Fortuna y el Acaso por otro y más adelante la aparición de la Dicha, precedida de la fanfarria del clarín «con corona y cetro» al «correrse dos cortinas» gradúan la espectacularidad de la representación y configuran un espacio de la ficción más complejo. El posible modelo escénico, propuesto por Ruano de la Haza (Ruano de la Haza 1991, pp. 201-205), de un tablado mucho más ancho que el habitual en los corrales madrileños, tomado del teatro construido en 1639 en el Hospital Real de Indios en la Ciudad de México, explica, a mi parecer adecuadamente, la acotación de sor Juana sobre la necesidad de dos cortinas para que la Dicha apareciera en la posición central (posición de privilegio visual), lo cual implicaría un desplazamiento escénico hacia el frente de los cuatro interlocutores y hacia un lado de la Música para dejar libre este espacio visual.

La primera pieza lírica cantada («Divina Lysi: permite») que sirve de pasaje de la loa a la primera jornada no rompe el ritmo escénico ya que desde antes de la aparición del personaje de la Dicha, nuestra autora indica que los personajes «cantan y representan» (Loa, 325, p. 108) con lo cual subraya su doble papel de dramaturga y directora de escena.

La claridad del texto espectacular planteado en esta primera parte ancilar del festejo creo que sugiere con bastante evidencia la conciencia de sor Juana como «autor» de compañía. Creo que esta conciencia es independiente de su presencia efectiva en el montaje de la representación. Aunque la pregunta queda abierta ies posible que una monja de clausura conociera tan bien los mecanismos escénicos sin estar en el tablado?

No se puede olvidar que el público teatral novohispano del siglo XVII era «un público habituado a todo tipo de fiestas, juegos y celebraciones de naturaleza masiva, bajo la dirección de los más estrafalarios dramaturgos, empresarios, divulgadores, abastecedores e histriones del teatro local que, por ese tiempo, pretendían transmitir una enseñanza moral, $o$, simplemente, deleitar a la concurrencia» (Maldonado 1992, p. 17) y que además conocía innumerables comedias que diariamente llegaban para representarse en los tablados rudimentarios o muy desarrollados de los corrales abiertos en la Ciudad de México y en Puebla. Sor Juana debió de estar muy al tanto de estos textos y expectativas ya que el funcionamiento escénico de su teatro no sólo es muy desarrollado, sino que en muchos aspectos innovador rebasando las convenciones calderonianas y de la comedia de capa y espada.

El habitual entremés situado entre la primera y la segunda jornada va aquí precedido de una letra («Bellísima María...») que establece un nexo estructural paralelo con la letra anterior que servía de pasaje entre la loa y la jornada. En el 
«Sainete primero de palacio» también encontramos elementos que nos señalan la intención de sor Juana de graduar el desarrollo dramático. Aunque el entremés se caracteriza por ser un género especializado (con la jácara y la mojiganga) simplemente en hacer reír y no en crear caracteres, en este caso tenemos un sainete en el cual aparece un verdadero personaje: el Alcalde y nuevamente cinco figuras simbólicas (que me parece pueden ser eco espectacular de la composición visual y representativa planteada por las cinco figuras de la loa). El contenido del sainete implica también un reflejo paródico del planteamiento de la loa ya que ahora es el Alcalde, plenipotenciario del desprecio de las damas de palacio, quien convoca a los cinco entes metafísicos: Amor, Obsequio, Respeto, Fineza y Esperanza ${ }^{7}$, para otorgar el premio que es el desprecio. El sainete como era de esperarse se caracteriza por su ironía y tono satírico ${ }^{8}$.

El sainete se abre con el Alcalde que se presenta a sí mismo cantando, nuevamente un sólido esquema de ritmo teatral que ahora pasa de la canción al texto cantado y que presumiblemente entra haciéndolo con lo cual modifica el espacio dramático que deja de ser la casa de los empeños y se convierte en el palacio conocido muy probablemente por la mayoría de los asistentes a esta representación teatral de homenaje.

En este sainete sor Juana no indica más que entradas y salidas de los personajes, las cuales por lógica escénica podemos suponer que son alternas a cada lado del fondo del tablado donde estarían situadas las puertas (esto sería válido tanto si aceptamos el modelo de Ruano de cinco espacios como si se trata del espacio de un corral tradicional con tres espacios). Esta alternancia en el lugar por donde salen a escena los personajes también crea un ritmo visual y podría establecer una relación implícita con las entradas y salidas de los personajes de la comedia.

El sainete concluye con el texto del Alcalde dejando desierto el premio y el paso a la segunda jornada de la comedia es directo sin ningún elemento estructural de relación, simplemente se va el alcalde y salen a escena don Carlos y Castaño. El lapso de tiempo entre una y otra acción no lo podemos determinar ya que obedece a la dinámica de la función. La segunda jornada nuevamente se cerrará con una letra cantada («Tierno pimpollo hermoso...») y dará paso al sainete segundo.

Este sainete es especialmente interesante ya que se refiere de manera muy directa al momento de la representación. En este sainete se deja de lado la ficción

Hildburg Schilling (1958, p. 234), sugiere que la Fineza y la Esperanza han de haber salido en traje de mujer.

8 A este respecto pueden verse las relaciones y diferencias con los modelos calderonianos en Hernández Araico (1996, pp. 316-342). 
de las alegorías y los personajes son los comediantes. El espacio dramático ahora es claramente el del teatro mismo y además en el momento mismo de la representación que se está llevando a cabo lo cual se hace explícito en el parlamento inicial del sainete:

ARIAS Mientras descansan nuestros camaradas
de andar las dos Jornadas
(que, vive Dios, que creo
que no fueran más largas de un correo;
pues si aquesta comedia se repite
juzgo que llegaremos a Cavite,
e iremos a un presidio condenados,
cuando han sido los versos forzados),
aquí, Muñiz amigo, nos sentemos
y toda la comedia murmuremos.

(Sainete Segundo 1-10, pp. 211-212)

El tono es completamente festivo y cargado de humor y de ironía. Parecería que sor Juana al escribirlo tiene muy presentes quiénes representan y en qué época lo harán, así como antecedentes de otra representación de una Celestina mestiza por Muñiz o la mención del autor Acebedo que pudiera ser Francisco de Acevedo, autor de El pregonero de Dios y patriarca de los pobres que se representó en octubre de 1684 (Schilling 1958, pp. 238-239), sin embargo la circunstancialidad del texto no impide que éste tenga una estructura dramática que funciona más allá de ese momento concreto.

Nuevamente podríamos identificar estos elementos como prueba de la conciencia de sor Juana como «autor» del montaje de la fiesta.

Por otra parte el sainete sirve para introducir elementos escenográficos como las dos sillas que se han usado en la segunda jornada y que se volverán a usar en la tercera. El paso a la comedia es directo y no hay que descartar que las sillas pudieran seguir en la escena construyendo el espacio de la primera jornada.

La comedia termina con la fórmula habitual que señala su fin y pide la benevolencia del público:

$\begin{array}{ll}\text { CASTAÑo: } & \text { Daca, que es el dedo malo, } \\ & \text { pues es él con quien encuentro. } \\ & \text { Y aquí, altísimos señores, } \\ & \text { y aquí, Senado discreto, } \\ & \text { Los empeños de una casa } \\ \text { dan fin. Perdonad sus yerros. }\end{array}$

(III, 3366-3371, p. 270)

Sin ningún texto de transición se inicia directamente el «Sarao de cuatro naciones» que es la parte teatral más evidente de festejo de homenaje. Su objetivo 
es halagar a los virreyes y en él el baile, componente habitual del espectáculo barroco, tiene también un sentido de homenaje. Nuevamente los bailes no se dejan al arbitrio de un director escénico ya que se aclara en las didascalias explícitas que «Júntanse las Naciones y tañen la Reina y cantan», «Tocan los instrumentos el Turdión y danzan», «Tocan los instrumentos la Jácara y la danzan». Ambos bailes son de tipo popular, integrados a los ambientes cortesanos desde tiempo atrás, tal como corresponde al modelo teatral habitual. Es evidente que el valor dramático de este sarao es mucho más limitado que el de la comedia o los sainetes, sin embargo está presente la idea del Nuevo y el Viejo Mundo como las dos partes del gran modelo imperial español. Escénicamente la diferenciación de la métrica usada por cada nación en sus textos tiene un sentido y un efecto distinto, así los españoles emplean el villancico, los negros coplas, los italianos versos de arte mayor (decasílabos y dodecasílabos) y los mexicanos romancillos hexasilábicos.

Los elementos que aquí hemos señalado nos hacen pensar en una sor Juana que no sólo tiene un amplio conocimiento literario del género teatral (sobre modelos calderonianos), sino que también tiene una amplia conciencia, que además plasma en este texto global, de los mecanismos de la representación. Es muy clara su idea de la fiesta barroca como un espectáculo teatral total que además reproduce la construcción de la función del corral o cortesana.

Estudiar la comedia de Los empeños de una casa con el conjunto de sus obras menores nos ayuda a entender mejor la capacidad creativa de sor Juana y su sensibilidad, instintiva, intelectual y emotiva, hacia la cultura del barroco de la que es altísimo exponente, pero también pone de manifiesto la complejidad escénica de sus creaciones lo que implica además de una sólida técnica dramática, un grado de conocimiento de lo espectacular que difícilmente se puede obtener y aplicar en la creación de una obra sin el contacto directo con el espacio escénico y la puesta en escena ante un público no por dispuesto menos conocedor.

Susana Hernández Araico ha propuesto que «se considere seriamente la probabilidad de que los sainetes y el fin de fiesta que acompañan la loa, comedia y canciones en sus primeras ediciones españolas no lo hayan hecho realmente en su primera producción entre 1683-1684» (Hernández Araico 1996, pp. 122-123). La probabilidad es muy alta, ya que extraña que una fiesta de tal desarrollo e importancia no haya tenido eco en su tiempo y además no se sabe en Nueva España de ninguna celebración palaciega con fiesta teatral completa como la que aquí hemos visto. Sin embargo ¿qué lleva a los editores a publicar el festejo teatral completo? ¿Demostraría así Sor Juana su dominio no sólo poético sino también escénico? No hay que olvidar que para un espíritu inquieto y en busca de retos intelectuales y creativos el hacer un espectáculo teatral completo desde una perspectiva escénica representaba la cúspide del arte dramático. Desde este punto 
de vista en realidad no importaría mucho si se representaron en conjunto en el momento supuesto de la bienvenida a los virreyes.

\section{BIBLIOGRAFÍA}

BRAVO, Dolores. 1992. «Sor Juana Inés de la Cruz. Antología» en Teatro mexicano. Historia y dramaturgia, t. VII, México, Consejo Nacional para la Cultura y las Artes.

CRUZ, Juana Inés de la, sor. 1957. Obras completas. Comedias, sainetes y prosa, t. IV, Alberto G. SALCEDA (ed.), México, Fondo de Cultura Económica.

CRUZ, Juana Inés de la, sor. [1683] 1989. Los empeños de una casa, Celsa Carmen GARCÍA VALDÉS (ed.), Barcelona, PPU.

CRUZ, Juana Inés de la, sor. [1692] 1995. Segundo volumen de las obras de Soror Juana Inés de la Crvz, monja profesa en el monasterio del señor san Geronimo de la Civdad de Mexico, Tomás López de Haro, Sevilla, ed. facsimilar, pról. Margo GLANTZ, México, Universidad Nacional Autónoma de México.

DÍEZ BORQUE, José María. 1992. «Fiesta sacramental barroca de El gran mercado del Mundo de don Pedro Calderón de la Barca», en Fiesta barroca, Madrid, Ministerio de Cultura, pp. 43-44.

GONZÁLEZ, Aurelio. 1993. «El espacio teatral en Los empeños de una casa», en Sara POOT-HERRERA (ed.), Y diversa de mí misma / entre vuestras plumas ando, México, El Colegio de México, pp. 269-277.

HERNÁNDEZ ARAICO, Susana. 1996. «Problemas de fecha y montaje en Los empeños de una casa de Sor Juana Inés de la Cruz», en Ysla CAMPBELL (ed.), El escritor y la crítica IV. Homenaje a Alfredo Hermenegildo, Ciudad Juárez, Universidad Autónoma de Ciudad Juárez, pp. 111-123.

HERNÁNDEZ ARAICO, Susana. 1997a. «Sor Juana's Los empeños de una casa. A Baroque Fête and a Theatrical Feat», en Robert LUER y Henry SULLIVAN (eds.), Hispanic Essays in honor of Frank P. Casa, New York, Peter Lang, pp. 316-342.

HERNÁNDEZ ARAICO, Susana. 1997b. «La innovadora fiesta barroca de Sor Juana: Los empeños de una casa», en Ysla CAMPBELL (ed.), El escritor y la crítica V. Homenaje a Marc Vitse, Ciudad Juárez, Universidad Autónoma de Ciudad Juárez, pp. 101-113.

MALDONADO, Humberto. 1992. «La teatralidad criolla del siglo XVII», en Teatro mexicano. Historia y dramaturgia, t. VIII, México, Consejo Nacional para la Cultura y las Artes. 
MASSIP, Francesc. 1992. El teatro medieval. Voz de la divinidad cuerpo de histrión, Barcelona, Montesinos.

MONTERDE, Francisco. 1946. «Teatro profano de Sor Juana», en Cultura Mexicana, México, Intercontinental, pp. 55-90.

PAILLER, Claire. 1973. «La question d'amour dans le theatre profane de Sor Juana Inés de la Cruz», TILAS 13-14, pp. 60-80.

POOT-HERRERA, Sara. 1993. «Las prendas menores de Los empeños de una casa» en Sara POOT-HERRERA (ed.), Y diversa de mí misma entre / vuestras plumas ando, México, El Colegio de México, pp. 257-267.

ROBLES, Antonio. [1665] 1946. Diario de sucesos notables (1665-1703), 3 vols., Antonio CASTRO LEAL (ed.), México, Porrúa.

RUANO DE LA HAZA, José María. 1991. «Los empeños de una casa. La puesta en escena de un festejo teatral de Sor Juana Inés de la Cruz en una casapalacio del Méjico colonial», en José María DÍEZ BORQUE (ed.), Espacios teatrales del Barroco español. XIII Jornadas de teatro clásico. Almagro 1990, Kassel, Reichenberger, pp. 199-220.

SCHILLING, Hildburg. 1958. Teatro profano en la Nueva España, México, Universidad Nacional Autónoma de México. 